\title{
2009 Donald R. Ulrich awards
}

\author{
Michel A. Aegerter
}

Published online: 14 April 2010

(C) Springer Science+Business Media, LLC 2010

Since 2003 the Donald R. Ulrich Awards are bestowed by the International Sol-gel Society (ISGS) during the biennial International Sol-gel Conference to young researchers who have been recognized for their distinguished achievement in the field of Sol-gel Science and Technology.

These Awards are bestowed in memoriam of Prof. Dr. Don Ulrich who was a senior Program Manager and Deputy Director of the Chemical and Atmospheric Sciences Directorate in the Air Force Office of Scientific Research from 1975 until 1990. Under his management major new initiatives in chemically synthesized materials (ceramics, ultrastructures, sol-gel processing, non-linear optical and ordered polymers, molecular composites, polymer alloys and multifunctional materials) have been established and had a worldwide impact. They contributed largely to what is known today as the Sol-gel field.

The candidatures for the 2007 Awards were opened to scientists younger than 35 years old by March 2009 whose research in the sol-gel field had already a major impact either in Basic and Applied Science or in Product or Product Oriented R\&D. Three submissions have been received for the first venue and one for the second. They have been analyzed by an International Committee composed of Dr. Florence Babonneau, Chair of the ISGS, Co-Editor of JSST, Dr. Michel Prassas, former ISGS Board member, Prof. Dr. Luis Carlos, Co-chair of the 2009 Conference, Prof. Dr. Rui Almeida, Chairman of the TC-16 Sol-gel Committee of the International Commission on

M. A. Aegerter $(\bowtie)$

Résidence Vert Pré, Ch.des Placettes, 6, 1041 Bottens, Switzerland

e-mail: michel.aegerter@bluewin.ch
Glass (ICG), Prof. Dr. Michel A. Aegerter, Editor-in-chief of the J. Sol-gel Science and Technology (JSST), the recipients of the 2007 Don Ulrich Awards, Dr. Jean-Marie Nedelec, Dr. Kiofumi Katagiri and Prof. Dr. Kazuki Nakanishi, ISGS Board member, Co-Editor of JSST, Chairman of the committee.

The following two candidates have been selected:

Basic and Applied Science: Dr. Paolo FALCARO, Materials Science \& Engineering division, Australian Commonwealth Scientific and Industrial Research Organisation, (CMSE, CSIRO), Australia.

Product or Product Oriented R\&D: Dr. Robert KREITER, Energy research Centre of the Netherlands (ECN), Netherlands.

Besides a diploma and the honor to deliver an invited lecture (see their paper in this issue), they each received the three volumes set of the Handbook of Sol-gel Science and Technology (S. Sakka editor) kindly offered by Springer, represented by Dr. David J. Packer, senior Editor who was present at the conference, as well as a check of 500 US\$ generously offered by Mrs. Eleanor Ulrich.

Dr. Paolo Falcaro (Fig. 1), born on January 17th 1975, graduated in Materials Science at Padova University (Italy) in 2002. He then received his $\mathrm{PhD}$ in Materials Engineering at Bologna University in 2006 under the supervision of Prof. Plinio Innocenzi and Prof. Massimo Guglielmi. He investigated sol-gel mesoporous coatings obtained by evaporation induced self assembly. The work, performed at the department of Mechanical Engineering (Materials Division) at Padova University, the Laboratorio di Scienza dei Materiali e Nanotecnologie (LMNT) and the Synchrotron of Elettra (IBN-Austrian beam line) has been relevant to highlight important variables of the selfassembly process. He also worked on the definition of a 


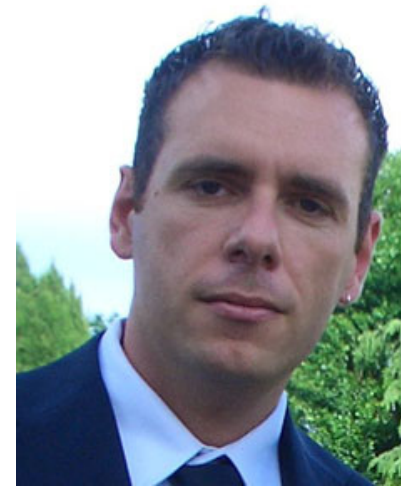

Fig. 1 Dr. Paolo Falcaro

reliable protocol to correctly identify the spatial groups of mesostructured materials from a 2D diffraction pattern. The work revealed the importance of synchrotron light (small angle X-ray scattering) to investigate in situ self assembly processes in sol-gel mesoporous films, together with the importance of infrared spectroscopy to study mesostructure features and behaviour.

The experience acquired in the synthesis of sol-gel materials allowed him to contribute to the development of mesostructured architectures as sensing platforms.

In 2005, he started a collaboration with a state of the art laboratory on nanotechnology research (Centro Interuniversitario Veneto per le nanotechnologie-CIVEN/ Nanofab). He managed the sol-gel area for industrial applications. He actively worked on sol-gel solutions for practical problems such as self-cleaning coatings based on the lotus effect and photocatalysis, inorganic and functionalized nanoparticles, hybrid nanocomposites for antiscratch coatings, thin films for high throughput screening for biomedical applications. He also continued to investigate mesoporous coatings and lithography processes collaborating with Prof. Innocenzi (LMNT Laboratory). His contribution has been relevant in mesostructure optimization and patterning of mesoporous coatings. He intensively worked on sol-gel combined with Deep X-ray Lithography (DXRL). In fact, X-rays have been revealed to be an external source that can locally tune material properties. He worked extending the technique to regular sol-gel thin and thick coatings for applications in which controlled areas with specific properties are needed. Even if still under investigation, this promising new patterning technology is interesting for basic science and promising for niche industrial applications.

In 2008 he got an international award from the Italian synchrotron (Elettra) for outstanding experiments using synchrotron light performed by a young scientist. During the same year he has been awarded for the innovative scientific contribution of his Ph.D thesis. He is cofounder of a company (Nadir srl) started after he received a national award for a relevant biomedical application combined with a proper business plan.

In 2009 he moved to the Australian Commonwealth Scientific and Industrial Research Organisation (CSIROAustralia) at the Materials Science \& Engineering division (CMSE), and started to work in Dr. Anita Hill group as an Office of the Chief Executive Science Leader Postdoctoral Fellow. He is currently developing organic, metallorganic and hybrid micro- and nano-porous systems involving sol-gel technology.

Dr. P. Falcaro, has therefore made significant contributions to the basic and applied sciences of sol-gel science and technology especially in the preparation and detailed characterization of functional coating materials.

Dr. Robert Kreiter (Fig. 2), born 16th of January 1976, studied Chemistry at Utrecht University (the Netherlands). In 2000 he obtained a master degree, after doing research on the synthesis of multinuclear organometallic complexes of platinum and palladium and their use as homogeneous catalysts.

Subsequently he started as a Ph.D. student on the development of triarylphosphines that contain amine substituents. These studies resulted in a new class of ammonium containing dendrimers with a triarylphosphine core. These dendritic phosphines were called Dendriphos and served as macromolecular ligands for highly active catalytic complexes. In addition, the ammonium groups in the macromolecular structure served as host for anions. Organic synthesis of macromolecules and coordination chemistry were fundamental for these studies. Nanoscopic Dendriphos coordination complexes and organometallic

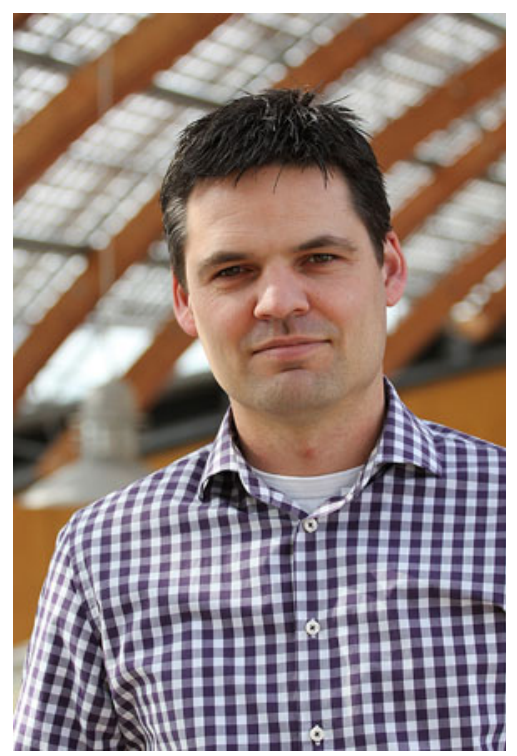

Fig. 2 Dr. Robert Kreiter 
complexes were studied with NMR, ESI-mass spectrometry, and single crystal X-ray crystallography. He graduated early 2006, on the thesis entitled: Triarylphosphines with Nucleophilic Substituents for the Construction of Multimetallic and Dendritic Assemblies.

Late 2005 he started working as a scientist for the Energy research Centre of the Netherlands (ECN) in the group Membrane Technology. The focus of this research group is to develop technology leading to a higher energy efficiency in (petro)chemical separation processes. His activities shifted from dendritic macromolecules to sol-gel nanoparticles and thin films. He focused on the development of microporous membranes from sol-gel nanoparticles. For this titania, zirconia, mixed metal oxides, and organic-inorganic hybrid silica were explored. One of his research interests is the tailoring of sol properties by the sol chemistry. The focus of his materials research was to find materials that resist the harsh chemical and hydrothermal conditions of many chemical processes. Since 2007, he is leading several projects at $\mathrm{ECN}$ in which high-performance materials for membrane applications are developed. One of his key responsibilities is to stimulate interaction between basic and applied science. To achieve this, he is actively involved in collaborations with local and international universities and he aims for strong interaction in the sol-gel field.

His main achievements in the membrane field are related to the development of organic-inorganic hybrid silica $\left(\mathrm{HybSi}^{\circledR}\right)$ membranes. These membranes show stable performance for several years in high-temperature dewatering

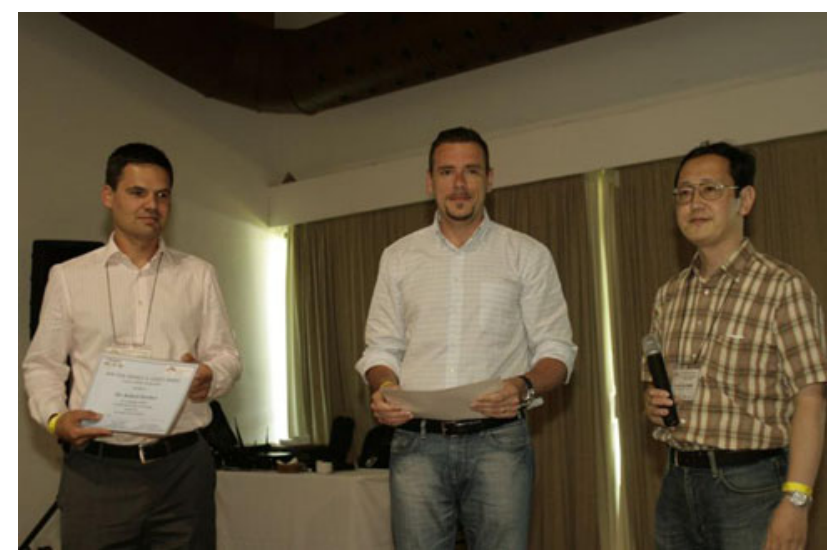

Fig. 3 From right to left: Prof. Dr. K. Nakanishi with the two Ulrich Award recipients, Dr. Falcaro and Dr. Kreiter of organics. In particular he has contributed to the development of $\mathrm{HybSi}^{\circledR}$ membranes with narrow pore size distributions. This was done by careful choice of the bridging precursor and of the preparation conditions. The resulting membranes are suitable for dewatering of methanol and (bio)ethanol. Based on this success, the $\mathrm{HybSi}^{\circledR}$ membranes are currently commercialized and membrane producers are contacted for large scale production. $\mathrm{He}$ is currently active in further expanding the scope these organic-inorganic hybrid silica membranes to other separation processes.

Next to membrane development he is interested in the use of high-throughput techniques for materials science. His main focus is to find generic tools that handle formulation, deposition, and functional testing of materials. He is actively promoting exchange of knowledge and materials between different research fields and constantly looking for synergy between different disciplines.

In short, Dr. Kreiter has made a strong contribution to the field of sol-gel membranes. The groundbreaking stability of the membrane material opens new directions in the field of sol-gel thin-films and membrane application research. Importantly, these findings have resulted in a new product that will impact the energy efficiency of industrial separation processes.

\section{Kazuki Nakanishi}

Chairman of the 2009 Donald R. Ulrich Awards

Department of Chemistry, Kyoto University, Kitashirakawa, Kyoto 606-8502, Japan

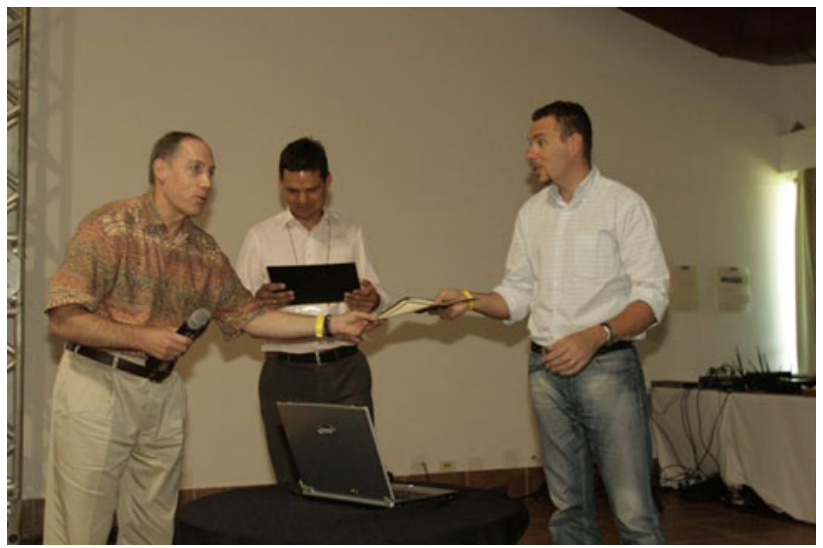

Fig. 4 Dr. David Packer, Springer executive editor, delivering the Ulrich Award diploma to Dr. Falcaro. In the middle, Dr. Kreiter 